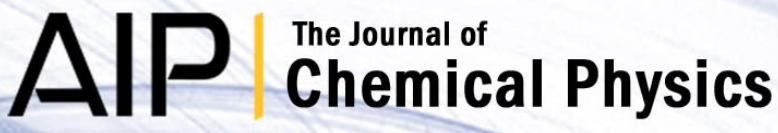

Long-range specific ion-ion interactions in hydrogen-bonded liquid films

Shinichi Enami and Agustín J. Colussi

Citation: J. Chem. Phys. 138, 184706 (2013); doi: 10.1063/1.4803652

View online: http://dx.doi.org/10.1063/1.4803652

View Table of Contents: http://jcp.aip.org/resource/1/JCPSA6/v138/i18

Published by the AIP Publishing LLC.

\section{Additional information on J. Chem. Phys.}

Journal Homepage: http://jcp.aip.org/

Journal Information: http://jcp.aip.org/about/about_the_journal

Top downloads: http://jcp.aip.org/features/most_downloaded

Information for Authors: http://jcp.aip.org/authors

\section{ADVERTISEMENT}

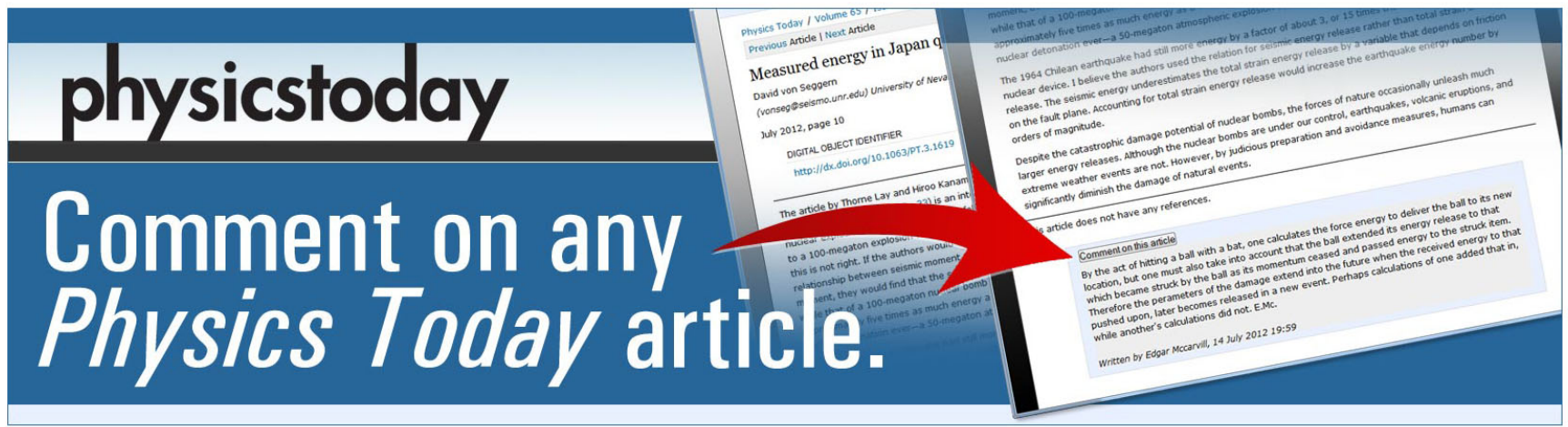




\title{
Long-range specific ion-ion interactions in hydrogen-bonded liquid films
}

\author{
Shinichi Enami ${ }^{1, a)}$ and Agustín J. Colussi ${ }^{2, a)}$ \\ ${ }^{1}$ The Hakubi Center for Advanced Research, Kyoto University, Kyoto 606-8302, Japan; \\ Research Institute for Sustainable Humanosphere, Kyoto University, Uji 611-0011, Japan; \\ and PRESTO, Japan Science and Technology Agency, Kawaguchi 332-0012, Japan \\ ${ }^{2}$ Ronald and Maxine Linde Center for Global Environmental Science, California Institute of Technology, \\ California 91125, USA
}

(Received 21 January 2013; accepted 18 April 2013; published online 9 May 2013)

\begin{abstract}
Anions populate fluid interfaces specifically. Here, we report experiments showing that on hydrogenbonded interfaces anions interact specifically over unexpectedly long distances. The composition of binary electrolyte $\left(\mathrm{Na}^{+}, \mathrm{X}^{-} / \mathrm{Y}^{-}\right)$films was investigated as a function of solvent, film thickness, and third ion additions in free-standing films produced by blowing up drops with a high-speed gas. These films soon fragment into charged sub-micrometer droplets carrying excess anions detectable in situ by online electrospray ionization mass spectrometry. We found that (1) the larger anions are enriched in the thinner (nanoscopic air-liquid-air) films produced at higher gas velocities in all (water, methanol, 2-propanol, and acetonitrile) tested solvents, (2) third ions (beginning at sub- $\mu \mathrm{M}$ levels) specifically perturb $\mathrm{X}^{-} / \mathrm{Y}^{-}$ratios in water and methanol but have no effect in acetonitrile or 2-propanol. Thus, among these polar organic liquids (of similar viscosities but much smaller surface tensions and dielectric permittivities than water) only on methanol do anions interact specifically over long, viz.: $\left\langle\mathrm{r}_{\mathrm{i}}-\mathrm{r}_{\mathrm{j}}\right\rangle / \mathrm{nm}=150(c / \mu \mathrm{M})^{-1 / 3}$, distances. Our findings point to the extended hydrogenbond networks of water and methanol as likely conduits for such interactions. () 2013 AIP Publishing LLC. [http://dx.doi.org/10.1063/1.4803652]
\end{abstract}

\section{INTRODUCTION}

Ion-specific effects are widespread, but nowhere are more critically manifested than at the fluid interfaces of biological structures. ${ }^{1-3}$ Action potentials, osmotic flows, energy transduction, ${ }^{4}$ and the stabilization of proteins are driven by ion concentration gradients across liquid films on hydrophobic biomaterials. ${ }^{3,5-10}$ Recent experiments in our laboratory revealed that ions interact specifically at the prototype airwater interface over separations that vastly exceed the range of direct electrostatic forces in any dielectric medium. ${ }^{11}$ Such long-range specific ion effects (LR-SIE) may be triggered by electrostatic and electrodynamic forces, but it is obvious that they must be powered by other mechanisms, such as the thermal fluctuations intrinsic to fluid interfaces. Recent simulations have shown that anions at the air-water interface specifically bias the height fluctuations of thermal capillary waves over extended domains. ${ }^{12-14}$ Given the importance of LRSIE across many fields, ${ }^{15-17}$ we deemed pertinent to inquire whether such mechanism is universal and applies to other liquids, ${ }^{1,18,19}$ or it is inherent to water. Herein, we report experiments addressing this fundamental question.

\section{EXPERIMENTAL SECTION}

In our experiments, we measure (in situ, via online electrospray ionization mass spectrometry, ESI-MS) relative an-

\footnotetext{
a) Authors to whom correspondence should be addressed. Electronic addresses: enami.shinichi.3r@kyoto-u.ac.jp and ajcoluss@caltech.edu
}

ion populations: $\chi=\left[\mathrm{X}^{-}\right] /\left[\mathrm{Y}^{-}\right]$, in the liquid films produced upon stretching drops of highly dilute sodium salt solutions by high-speed nitrogen gas. We investigate $\chi$ for different $\left(\mathrm{X}^{-} / \mathrm{Y}^{-}\right)$anion pairs in four solvents as functions of gas velocity, $v_{\mathrm{G}}$, and third anion $\left(\mathrm{Z}^{-}\right)$additions in the $0.1-100 \mu \mathrm{M}$ range. ${ }^{11}$ Detailed descriptions of our experimental setup have been presented before. ${ }^{20-22}$ Here, we summarize the key events that give rise to our mass spectral signals. Liquid solutions (injected as jets into the spraying chamber of the mass spectrometer) are sheared into primary drops by means of a co-directional highspeed nebulizer gas. ${ }^{23}$ The ejected primary drops are flattened by the gas, and then suddenly stretched windward into rimmed thin-film bags. ${ }^{24}$ In this process, cations are demonstrably drawn to the rim whereas anions largely remain in the film (see below). Figure 1 is a schematic illustration of the primary droplet breakup and charge separation. The thickness of the film $\delta$ (which depends on $v_{\mathrm{G}}$, the surface tension, $\sigma$, and dynamic viscosity, $\eta_{\mathrm{L}}$, of the liquid) ${ }^{25,26}$ is not uniform but increases from the center of the bag toward the rim. Fluid dynamics considerations dictate that the average thickness of the film, $\langle\delta\rangle$, is an inverse function of $v_{\mathrm{G}} .{ }^{27-29}$ These rimmed bags are dynamically unstable and fragment within tens of microseconds into smaller, submicrometer-sized, electrically charged secondary droplets (Figure 1). ${ }^{30}$ The enhanced surface and electrostatic energies of the polarized stretched films are drawn from the kinetic energy of the gas. Since the kinetic energy density of the gas can deform only primary drops of $d_{d} \sim 1 \mathrm{~mm}$ diameter under present conditions, ${ }^{24}$ the breakup of the bag into charged secondary droplets is the primordial, one- 


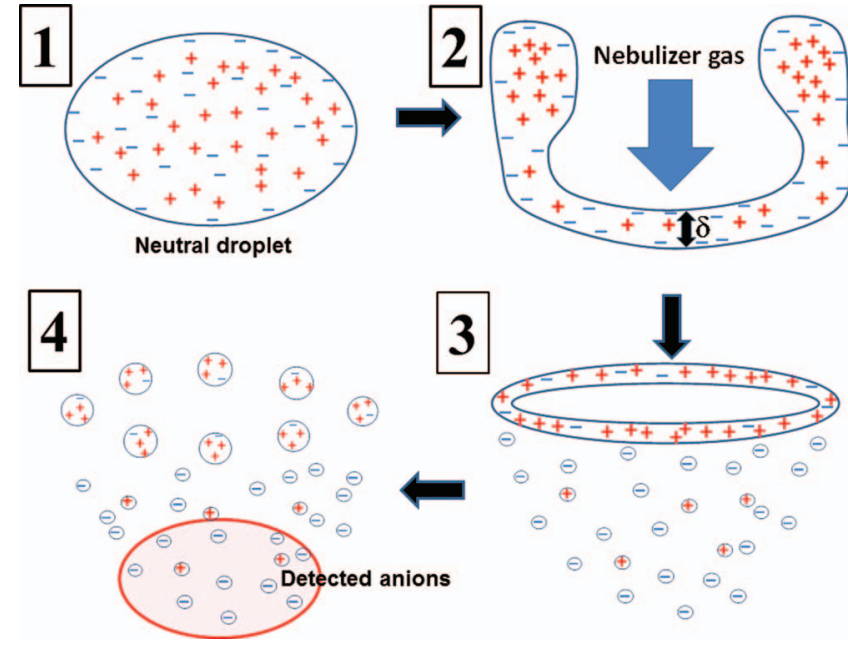

FIG. 1. Schematic illustration of a droplet breakup and charge separation mechanism. $\delta$ is the thickness of the film. In our experiments, we sample the anions contained in the sub-micrometer-droplets generated from the center of the film, which are detected in situ by online electrospray ionization mass spectrometry. Anions having the largest propensities for the air-liquid interface, such as $\mathrm{I}^{-}$and $\mathrm{ClO}_{4}{ }^{-}$, produce the most intense mass signals. See text for details.

time event in which net charges (those detected by mass spectrometry) are created from the neutral inflowing solutions. It is apparent that, since the amount of net charge created during breakup should increase with the kinetic energy density of the nebulizer gas, absolute signal intensities will generally increase with $v_{\mathrm{G}}$. Thus, information on ion selectivity is contained in relative, $\chi=\left[\mathrm{X}^{-}\right] /\left[\mathrm{Y}^{-}\right]$, rather than absolute anion signals. As expected from the preceding analysis, secondary droplets originating from the film are negatively charged because they contain excess anions, whereas the coarser ones arising from the rims carry net positive charge (Figure 1). ${ }^{31,32}$ The aerodynamic droplet breakup mechanism presented here is consistent with previous reports ${ }^{28,31}$ and has been confirmed by Zilch et al. ${ }^{31}$ Secondary droplets are swept by the gas, wherein rapidly shrink via solvent evaporation leading to the crowding of their excess charges. Solvent evaporation is minimal prior to film breakup, as evidence by the fact that the titration curves of carboxylic acids and trimethylammonium determined in this setup were identical with the ionization constants reported in the literature (i.e., $\mathrm{pK}_{\mathrm{a}}$ $\sim 4.8$ and 9.8, respectively). ${ }^{21,22,33}$ Droplets eventually become Rayleigh-unstable and undergo a cascade of Coulomb explosions whose outcome is the ejection of bare single ions to the gas-phase. ${ }^{34,35}$ Note that Coulomb explosions, in contrast with the aerodynamic breakup of primary droplets described above, arise from repulsion among like charges and therefore preserve the overall net charges of the initial ensemble of negatively charged secondary droplets. It should be emphasized that these experiments, in contrast with the static surfaces employed in most studies, performed as they are on fast-flowing, continuously refreshed liquid jets, minimize surface contamination. Further experimental details and validation tests could be found in Fig. S1 in the supplementary material ${ }^{67}$ and in Refs. 22 and 33.

\section{RESULTS AND DISCUSSION}

Figure 2 shows the results of experiments conducted on (5 $\mu \mathrm{M} \mathrm{NaI} / 5 \mu \mathrm{M} \mathrm{NaBr}$ ) solutions in $\mathrm{H}_{2} \mathrm{O}$ at various gas velocities. Individual $\mathrm{I}^{-}(\mathrm{m} / \mathrm{z}=127), \mathrm{Br}^{-}(\mathrm{m} / \mathrm{z}=79+81) \mathrm{sig}-$ nal intensities change significantly as gas velocity increases from $v_{\mathrm{G}}=46$ to $274 \mathrm{~m} / \mathrm{s}$ (inset), whereas the fractional iodide population: $\phi=\left[\mathrm{I}^{-}\right] /\left(\left[\mathrm{I}^{-}\right]+\left[\mathrm{Br}^{-}\right]\right)=\chi /(1+\chi)$, follows a: $\phi=0.493+0.433 v_{\mathrm{G}} /\left(129+v_{\mathrm{G}}\right)$, functional response. It is apparent that, as expected, $\phi$ approaches 0.5 (i.e., the limiting value expected for the bulk equimolar solution) as $v_{\mathrm{G}} \rightarrow 0$, and tends to $\phi \rightarrow 1$ as $v_{\mathrm{G}} \rightarrow \infty$. We interpret these results as significant evidence that in our experiments we sample liquid films whose thicknesses $\langle\delta\rangle$ and, hence, their composition are controlled aerodynamically by gas flow. Furthermore, considering that ion segregation can be significant only in the outermost layers of the liquid, ${ }^{12,36-38}$ the films produced at the highest $v_{\mathrm{G}}$ must reach $\langle\delta\rangle<1 \mathrm{~nm}$ thicknesses immediately before bursting. Accordingly, we found that $\phi$ is only weakly dependent on the velocity of the liquid jet $v_{\mathrm{L}}$ $\left(v_{\mathrm{L}}=0.21 \mathrm{~cm} \mathrm{~s}^{-1} V_{L} ; V_{L}\right.$ is the volumetric flow of the injected liquid solution in $\mu \mathrm{l} / \mathrm{min}$ ) as expected from the fact that $\left(v_{\mathrm{G}}-v_{\mathrm{L}}\right) \sim v_{\mathrm{G}}$ under all conditions (Fig. S3 in the supplementary material $\left.{ }^{67}\right)$. Related experiments on $(5 \mu \mathrm{M} \mathrm{NaI} /$ $5 \mu \mathrm{M} \mathrm{NaBr}$ ) solutions in methanol $(\mathrm{MeOH})$, acetonitrile (AN), and 2-propanol (IPA) led to similar, albeit not identical results (Figure 3) (see also Appendix S1 in the supplementary material $^{67}$ ).

Thus, everything happens as if the experiments at higher gas velocities probe increasingly thinner interfacial layers where $\mathrm{I}^{-}$and $\mathrm{Br}^{-}$concentration profiles resemble, at least qualitatively, those illustrated in Figure 4 (see below). In line with the results of spectroscopic experiments performed over much longer time scales, ${ }^{36}$ we find that anions are effectively segregated as if those having larger propensities for the air-liquid interface are enriched in the thinner sectors of the stretched bags. In other words, ion gradients over the span of stretched bags approach those expected from equilibrium

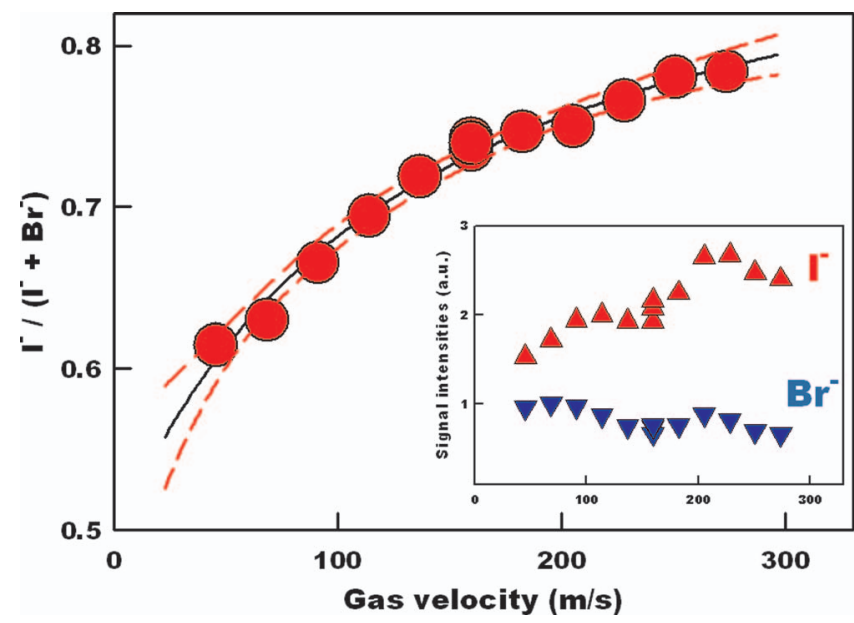

FIG. 2. The fractional iodide population: $\phi=\left[\mathrm{I}^{-}\right] /\left(\left[\mathrm{I}^{-}\right]+\left[\mathrm{Br}^{-}\right]\right)$ $=\phi=0.49+0.43 v_{\mathrm{G}} /\left(129+v_{\mathrm{G}}\right)$ in films of $(5 \mu \mathrm{M} \mathrm{NaI}+5 \mu \mathrm{M} \mathrm{NaBr})$ solutions in $\mathrm{H}_{2} \mathrm{O}$ as functions of gas velocity $\nu_{\mathrm{G}}$. Dashed lines correspond to $95 \%$ confidence limits. (Inset) ESI mass spectral $\mathrm{I}^{-}(\mathrm{m} / \mathrm{z}=127)$ and $\mathrm{Br}^{-}$ $(\mathrm{m} / \mathrm{z}=79+81)$ signal intensities. 


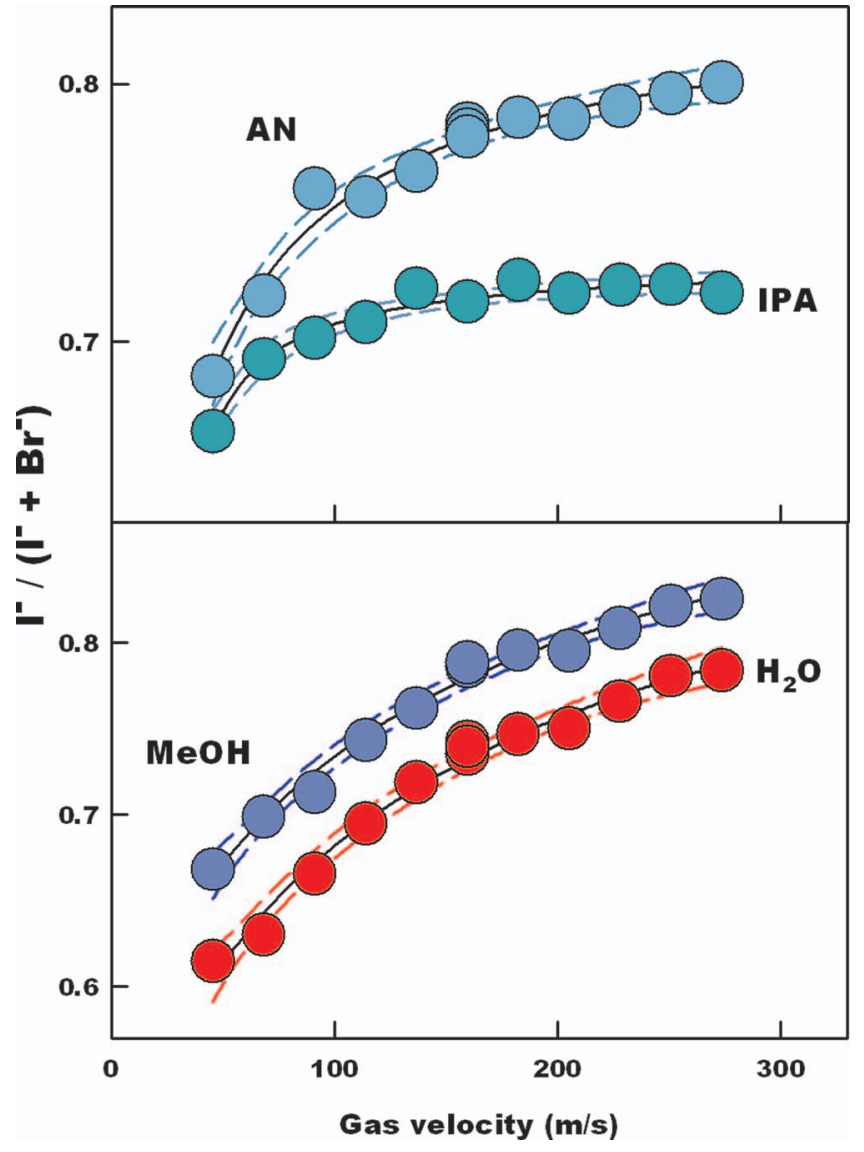

FIG. 3. The fractional iodide population: $\phi=\left[\mathrm{I}^{-}\right] /\left(\left[\mathrm{I}^{-}\right]+\left[\mathrm{Br}^{-}\right]\right)$in films of $\left(5 \mu \mathrm{M} \mathrm{NaI}+5 \mu \mathrm{M} \mathrm{NaBr}\right.$ ) solutions in $\mathrm{H}_{2} \mathrm{O}$, methanol ( $\left.\mathrm{MeOH}\right)$, acetonitrile (AN), and 2-propanol (IPA) as functions of gas velocity $v_{\mathrm{G}}$. Solid lines are regressions to $\phi=\mathrm{A}+\mathrm{B} v_{\mathrm{G}} /\left(\mathrm{C}+v_{\mathrm{G}}\right)$ functionals. Dashed lines correspond to $95 \%$ confidence limits.

distribution considerations. Although hydrodynamics plays a key role in this phenomenon, ${ }^{24}$ typical values of ion diffusion coefficients, $D \sim 2 \times 10^{-5} \mathrm{~cm}^{2} \mathrm{~s}^{-1}$, and representative film lifetimes, $\tau \sim 10^{-5} \mathrm{~s}$, lead to estimated mean diffusive displacements: $\lambda=(2 D \tau)^{1 / 2} \sim 2 \times 10^{-5} \mathrm{~cm}$, that are larger than the average thickness of the (nano) films, suggesting that diffusion may assist ions to achieve equilibration. Whether the relative ion abundances sampled in our experiments do correspond to fully equilibrated distributions is the subject of ongoing studies.

We have previously suggested that the closer approach of the larger ions to air-liquid interfaces could be the outcome of the actions of a repulsive (toward the interface) force, $f_{\text {rep }}$, a net attractive force, $f_{\text {atr }}$, due the unbalanced dispersive forces exerted by the whole liquid on interfacial layers, i.e., those accounting for macroscopic liquid cohesion (see Appendix S2 in the supplementary material $\left.{ }^{67}\right),{ }^{11,39-41}$ and the negative entropy of mixing associated with the creation of interfacial concentration gradients. The essential point for present purposes is that anion concentration profiles should peak at different depths, $z=1-\delta$, depending on their ionic radii. Our experiments are clearly consistent with such scenario. However, since the interfacial $\mathrm{I}^{-}$and $\mathrm{Br}^{-}$profiles evaluated on these premises (Figure 4) qualitatively match those obtained by molecular dynamics calculations, ${ }^{10,13,42,43}$ our experiments

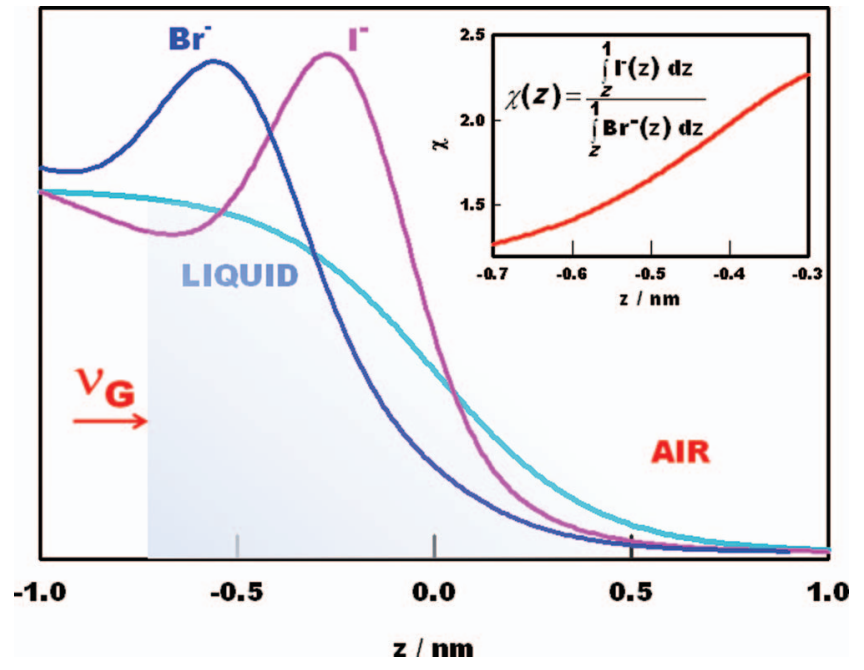

FIG. 4. A depiction of interfacial concentration profiles and derived anion ratios: $\chi(z)=\left[\mathrm{I}^{-}\right] /\left[\mathrm{Br}^{-}\right]$(inset), as functions of depth $z$. Film thickness: $\delta=1-z$, is assumed to be an inverse function of gas velocity $v_{\mathrm{G}} .{ }^{23,24,28,29}$ $z=0$ corresponds to the position of the Gibbs dividing surface.

do not discriminate among different explanations of the mechanism of anion enrichment at air-liquid interfaces. ${ }^{9,10,12,44}$

Since the average ion-ion separation $\left\langle\mathrm{r}_{\mathrm{i}}-\mathrm{r}_{\mathrm{j}}\right\rangle=87 \mathrm{~nm}$ at $5 \mu \mathrm{M}\left(\left\langle\mathrm{r}_{\mathrm{i}}-\mathrm{r}_{\mathrm{j}}\right\rangle / \mathrm{nm}=150(c / \mu \mathrm{M})^{-1 / 3}\right)$ exceeds the Bjerrum length (the interionic separation between two monovalent ions at which their mutual electrostatic energy equals the average thermal energy, $\left.k_{B} T\right)^{45} \lambda_{B}=e^{2} /\left(4 \pi \varepsilon_{0} \varepsilon k_{B} T\right)=0.7$ or $56 \mathrm{~nm}$ in $\mathrm{H}_{2} \mathrm{O}(\varepsilon=78)$ or vacuum $(\varepsilon=1)$, respectively, the expectation is that anions should behave independently of each other in $<5 \mu \mathrm{M}$ solutions. However, this is clearly not the case. Figure 5 shows that in the presence of $\mathrm{ClO}_{4}{ }^{-}, \mathrm{I}^{-}$(in contrast with the experiments of Figure 2) is increasingly depleted in thinner films. The larger but less polarizable $\mathrm{ClO}_{4}{ }^{-39,40,46}$ clearly outcompetes $\mathrm{I}^{-}$for the occupation of the film sectors sampled in our experiments. $\left(\mathrm{NaBr} / \mathrm{NaNO}_{3}\right)$ solutions behave very differently. We find that $\mathrm{Br}^{-}$and $\mathrm{NO}_{3}{ }^{-}$, both of which

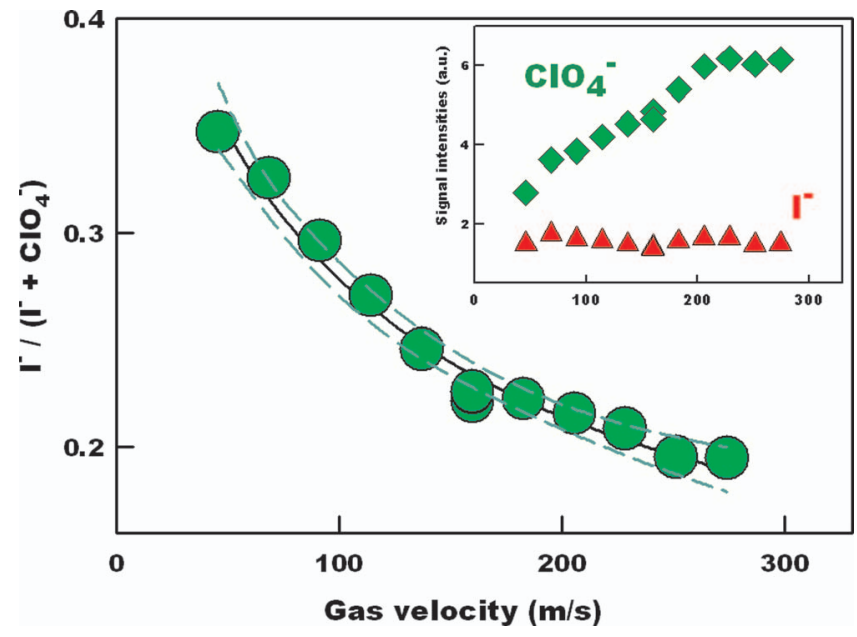

FIG. 5. The fractional iodide population: $\phi=\left[\mathrm{I}^{-}\right] /\left(\left[\mathrm{I}^{-}\right]+\left[\mathrm{ClO}_{4}{ }^{-}\right]\right)=\phi$ $=0.49-0.40 v_{\mathrm{G}} /\left(86+v_{\mathrm{G}}\right)$ in films of $\left(5 \mu \mathrm{M} \mathrm{NaI}+5 \mu \mathrm{M} \mathrm{NaClO}{ }_{4}\right)$ solutions in $\mathrm{H}_{2} \mathrm{O}$ as functions of gas velocity $\nu_{\mathrm{G}}$. Dashed lines correspond to 95\% confidence limits. (Inset) ESI mass spectral $\mathrm{I}^{-}(\mathrm{m} / \mathrm{z}=127)$ and $\mathrm{ClO}_{4}{ }^{-}$ $(\mathrm{m} / \mathrm{z}=99+101)$ signal intensities. 


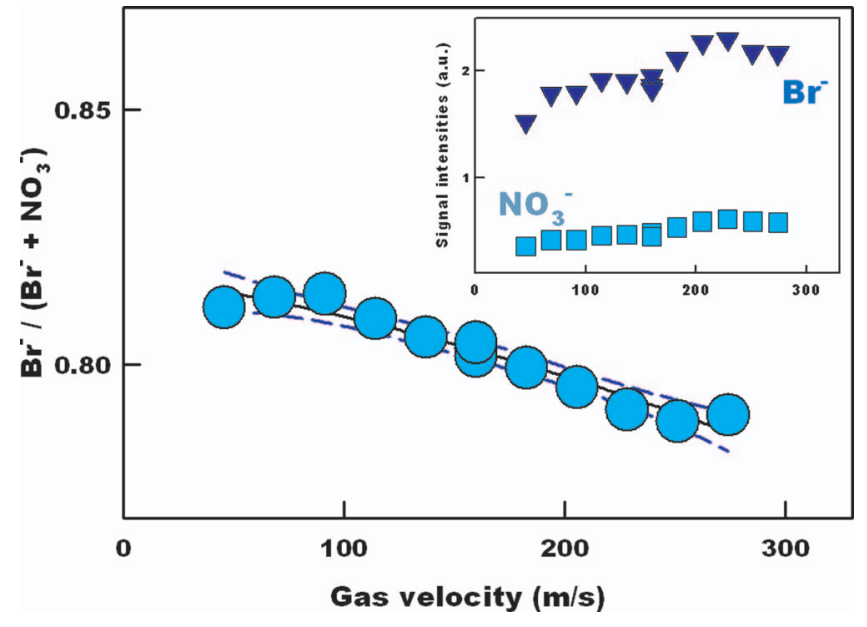

FIG. 6. The fractional bromide population: $\phi=\left[\mathrm{Br}^{-}\right] /\left(\left[\mathrm{Br}^{-}\right]+\left[\mathrm{NO}_{3}{ }^{-}\right]\right)$ in films of $\left(5 \mu \mathrm{M} \mathrm{NaBr}+5 \mu \mathrm{M} \mathrm{NaNO}_{3}\right)$ solutions in $\mathrm{H}_{2} \mathrm{O}$ as functions of gas velocity $v_{\mathrm{G}}$. Solid lines are regressions to $\phi=\mathrm{A}+\mathrm{B} v_{\mathrm{G}} /\left(\mathrm{C}+v_{\mathrm{G}}\right)$ functionals. Dashed lines correspond to $95 \%$ confidence limits. (Inset) ESI mass spectral $\mathrm{Br}^{-}(\mathrm{m} / \mathrm{z}=79+81)$ and $\mathrm{NO}_{3}{ }^{-}(\mathrm{m} / \mathrm{z}=62)$ signal intensities.

have much lower propensities than $\mathrm{ClO}_{4}{ }^{-}$and $\mathrm{I}^{-}$for the airwater interface, ${ }^{39,40}$ are similarly enriched in the sampled sectors of thinner films (Figure 6). The obvious interpretation (with reference to Fig. 4) is that the concentration profiles of both $\mathrm{Br}^{-}$and $\mathrm{NO}_{3}{ }^{-}$peak at depths larger than the thickest films monitored in our experiments. Together, these results represent evidence that (1) our technique is surface-sensitive and (2) the depth of the interfacial layers sampled in our experiments is reproducibly controlled by $v_{\mathrm{G}}$. In other words, the interfacial region has been microtomized by aerodynamic means.

Further insight into LR-SIE in thin films is provided by experiments involving the addition of variable concentrations of a third anion $\mathrm{Z}^{-}\left(\mathrm{ClO}_{4}{ }^{-}\right.$or $\left.\mathrm{NO}_{3}{ }^{-}\right)$to $(5 \mu \mathrm{M}$ $\mathrm{NaI} / 5 \mu \mathrm{M} \mathrm{NaBr}$ ) solutions in $\mathrm{H}_{2} \mathrm{O}$ at low and high $v_{\mathrm{G}}$ (Figure 7), and in organic solvents at a high $v_{\mathrm{G}}$ (Figure 8). Below $\sim 10 \mu \mathrm{M}$, neither $\mathrm{ClO}_{4}{ }^{-}$nor $\mathrm{NO}_{3}{ }^{-}$have detectable effects on $\chi=\left[\mathrm{I}^{-}\right] /\left[\mathrm{Br}^{-}\right]$in the aqueous films produced at low gas velocity $\nu_{\mathrm{G}}=66 \mathrm{~m} / \mathrm{s}$. In contrast, the addition of $\sim 1 \mu \mathrm{M}$ $\mathrm{ClO}_{4}{ }^{-}$significantly depresses $\chi$ in the thin films produced at $v_{\mathrm{G}}=274 \mathrm{~m} / \mathrm{s}$. Thus, $\mathrm{ClO}_{4}{ }^{-}$specifically displaces $\mathrm{I}^{-}$(as expected from the results of Figure 5) more strongly than it does $\mathrm{Br}^{-}$. Clearly, this effect is not generic, e.g., mediated by the increased charge density of the films, ${ }^{47}$ but chemically specific in a concentration range where average ion-ion separations exceed $\sim 100 \mathrm{~nm}$.

Similar three-anion experiments performed in different solvents are informative regarding the actual mechanism underlying LR-SIE. Conjecturing that the hydrogen bonding network of water might be involved in this phenomenon, we tested hydroxylic solvents, $\mathrm{MeOH}$ and IPA, and a polar non-hydroxylic solvent, AN, as propagating media. These organic solvents have similar dynamic viscosities, $\eta_{\mathrm{L}}$, but much smaller surface tensions, $\sigma$, and dielectric permittivities, $\varepsilon$, than water (see Table I). The large differences in surface tensions should have a significant impact on the amplitude and dynamics of capillary waves. ${ }^{14,48}$ However, whereas the ex-

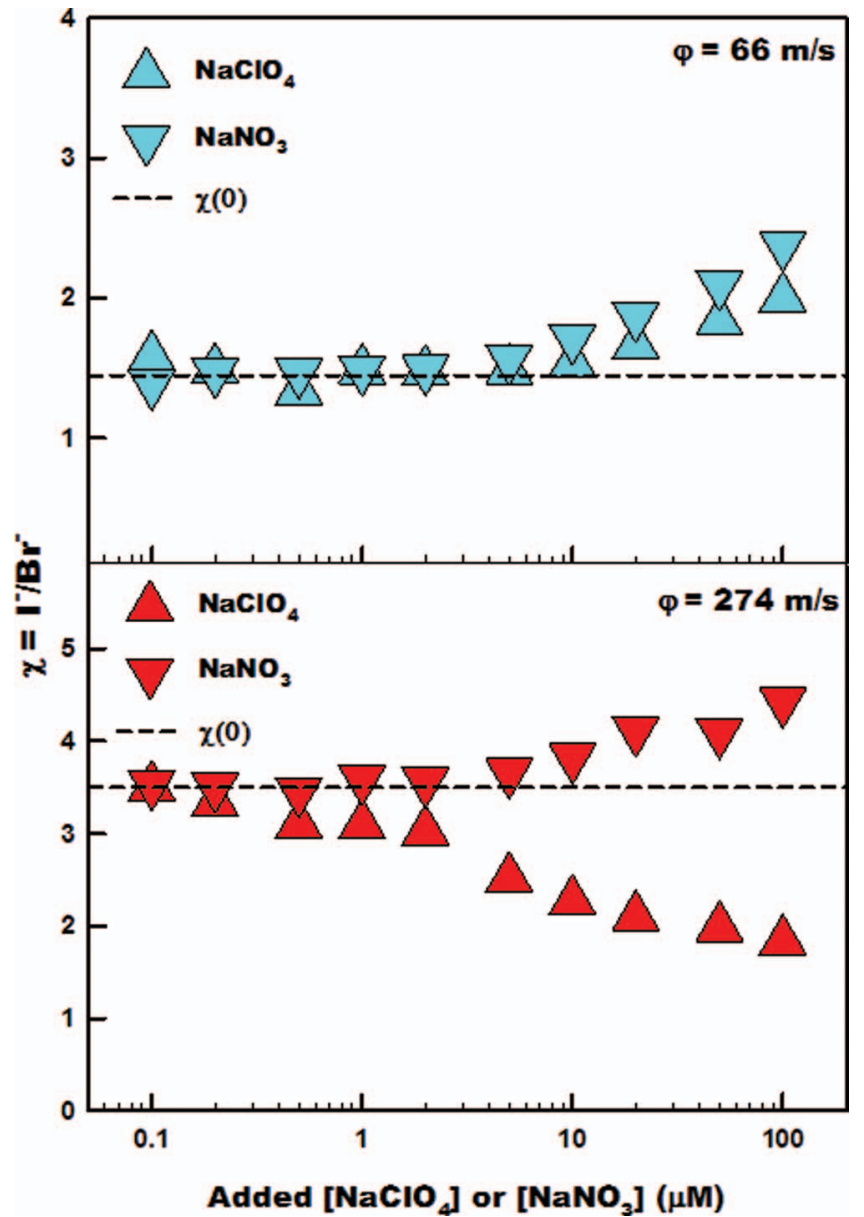

FIG. 7. Semi-logarithmic plots of the ratio of ESI mass spectral signal intensities $\chi=\mathrm{I}^{-} / \mathrm{Br}^{-}$in films of $(5 \mu \mathrm{M} \mathrm{NaI}+5 \mu \mathrm{M} \mathrm{NaBr})$ solutions in $\mathrm{H}_{2} \mathrm{O}$ as a function of added $\mathrm{NaClO}_{4}$ or $\mathrm{NaNO}_{3}$ at $v_{\mathrm{G}}=66 \mathrm{~m} / \mathrm{s}$ (upper panel) or $274 \mathrm{~m} / \mathrm{s}$ (lower panel) gas velocities. Dashed lines correspond to the values of $\chi(0)=1.45$ and 3.50 , respectively.

periments in $\mathrm{MeOH}$ closely reproduce those in water, $\mathrm{ClO}_{4}{ }^{-}$ (up to $20 \mu \mathrm{M}$ ) has no effect whatsoever on $\chi=\left[\mathrm{I}^{-}\right] /\left[\mathrm{Br}^{-}\right]$in IPA or AN (Figure 8). The failure of AN to propagate LR-SIE confirms our conjecture, but the experiments in IPA appear to contradict it. However, we consider that the latter result represents a false negative because IPA, in contrast with $\mathrm{H}_{2} \mathrm{O}$ and $\mathrm{MeOH},{ }^{49-56}$ lacks an extensive H-bond network. Alkyl groups restrict the number of configurations amenable to hydrogen bonding, and this effect increases with the number and size of the alkyl groups surrounding O-H moieties. ${ }^{57-59}$ Molecular dynamics calculations have shown that the percolating hydrogen-bonded network of water persists in $\mathrm{H}_{2} \mathrm{O}-\mathrm{MeOH}$ liquid mixtures up to $\mathrm{x}_{\mathrm{MeOH}} \sim 0.5 .{ }^{49}$ Thus, our experimental

TABLE I. Solvent properties at $298 \mathrm{~K}$.

\begin{tabular}{lcccc}
\hline \hline Solvent & $\begin{array}{c}\text { Surface tension } \\
\sigma(\mathrm{mN} / \mathrm{m})\end{array}$ & $\begin{array}{c}\text { Dynamic viscosity } \\
\eta(\mathrm{mPa})\end{array}$ & $\begin{array}{c}\text { Dielectric } \\
\text { constant } \varepsilon\end{array}$ & $\begin{array}{c}\text { Density } \\
\rho_{l}\left(\mathrm{~kg} / \mathrm{m}^{3}\right)\end{array}$ \\
\hline Water & 72.7 & 0.89 & 78 & 997 \\
Methanol & 22.1 & 0.54 & 33 & 787 \\
Acetonitrile & 28.7 & 0.37 & 38 & 777 \\
2-propanol & 23.3 & 2.04 & 20 & 786 \\
\hline
\end{tabular}




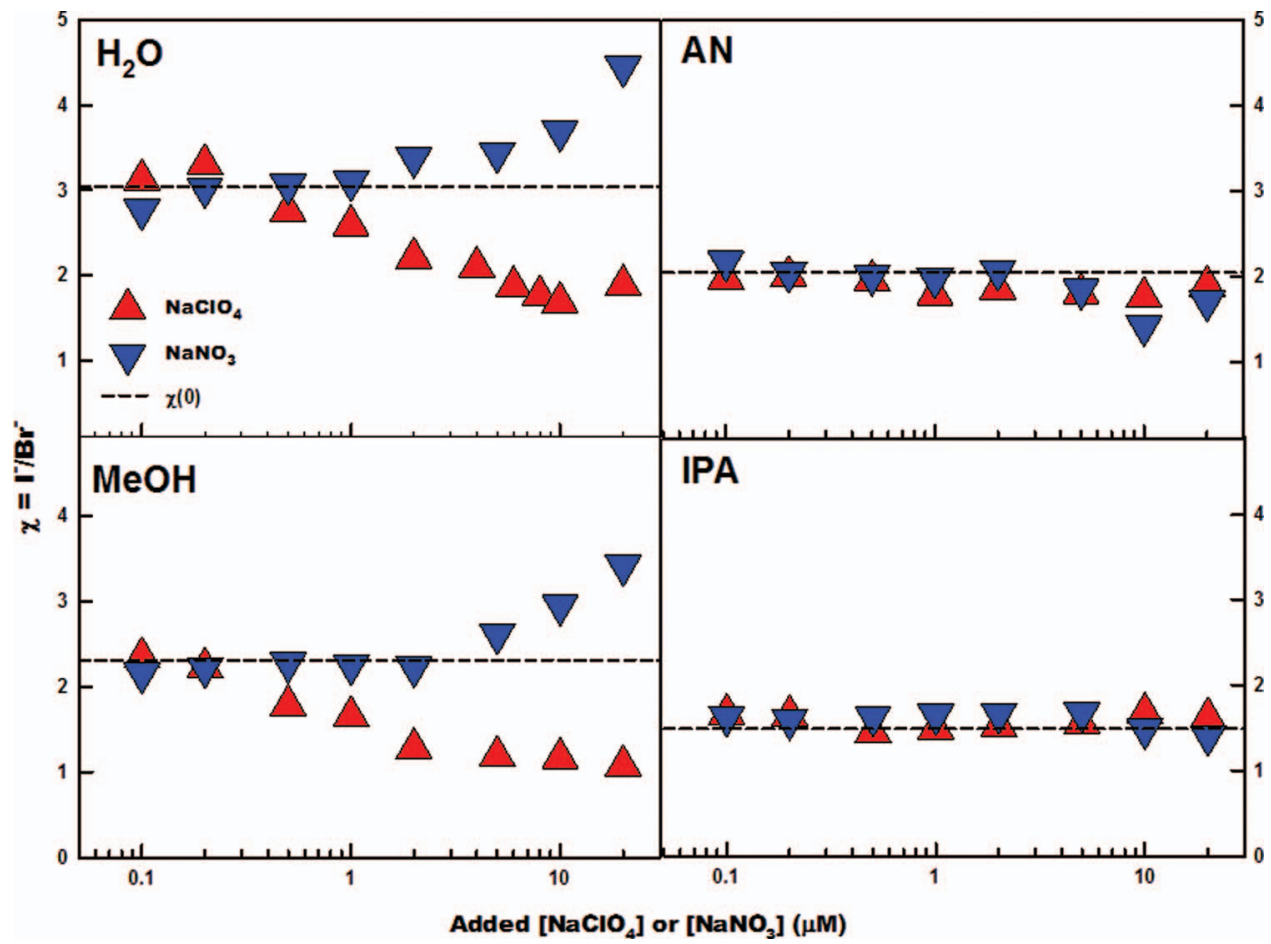

FIG. 8. Semi-logarithmic plots of the ratio of ESI mass spectral signal intensities $\chi=\mathrm{I}^{-} / \mathrm{Br}^{-}$in films of $(1 \mu \mathrm{M} \mathrm{NaI}+1 \mu \mathrm{M} \mathrm{NaBr})$ solutions in $\mathrm{H}_{2} \mathrm{O}$, methanol $(\mathrm{MeOH})$, acetonitrile (AN), or 2-propanol (IPA) as a function of added $\mathrm{NaClO}_{4}$ or $\mathrm{NaNO}_{3}$ at $v_{\mathrm{G}}=160 \mathrm{~m} / \mathrm{s}$. Dashed lines correspond to values of $\chi(0)$.

results are consistent with the involvement of such extended networks in LR-SIE at air-liquid interfaces. ${ }^{60-66}$

In summary, we demonstrated that the depth of the interfacial layers sampled in our experiments is controlled by nebulizer gas velocity $v_{\mathrm{G}}$. We found that the larger, rather than the more polarizable, anions are systematically enriched in the thinner (nanoscopic air-liquid-air) films produced at higher gas velocities in all tested solvents (water, methanol, 2propanol, and acetonitrile). Addition of third ions (beginning at sub- $\mu \mathrm{M}$ levels) specifically perturbs the $\mathrm{I}^{-} / \mathrm{Br}^{-}$ratio in water and methanol solutions but has no effect in acetonitrile or 2-propanol. Thus, only methanol among these polar organic liquids appears to be able to connect specifically ions separated by long distances along its aerial interface. Our findings suggest that the extended hydrogen-bond networks of water and methanol may play a decisive role in this phenomenon.

\section{ACKNOWLEDGMENTS}

This work was financially supported by the Japan Science and Technology Agency (JST) PRESTO program, and by the U.S. National Science Foundation (NSF) Grant No. AGS-1238977. We thank H. Mishra and M. R. Hoffmann (Caltech) for helpful discussion. We are grateful to Professor Theofanous (UC Santa Barbara) for valuable advice.

${ }^{1}$ N. Peruzzi, B. W. Ninham, P. Lo Nostro, and P. Baglioni, J. Phys. Chem. B 116, 14398 (2012).

${ }^{2}$ L. M. Pegram, T. Wendorff, R. Erdmann, I. Shkel, D. Bellissimo, D. J. Felitsky, and M. T. Record, Proc. Natl. Acad. Sci. U.S.A. 107, 7716 (2010).

${ }^{3}$ I. Kalcher, D. Horinek, R. R. Netz, and J. Dzubiella, J. Phys.: Condens. Matter 21, 424108 (2009).

${ }^{4}$ P. Mitchell, Nature (London) 191, 144 (1961).
${ }^{5}$ J. N. Wilking, T. E. Angelini, A. Seminara, M. P. Brenner, and D. A. Weitz, MRS Bull. 36, 385 (2011).

${ }^{6}$ N. Schelero and R. von Klitzing, Soft Matter 7, 2936 (2011).

${ }^{7}$ J. M. Borah, S. Mahiuddin, N. Sarma, D. F. Parsons, and B. W. Ninham, Langmuir 27, 8710 (2011).

${ }^{8}$ W. Kunz, Curr. Opin. Colloid Interface Sci. 15, 34 (2010).

${ }^{9}$ D. F. Parsons, M. Bostrom, P. Lo Nostro, and B. W. Ninham, Phys. Chem. Chem. Phys. 13, 12352 (2011).

${ }^{10}$ R. R. Netz and D. Horinek, Annu. Rev. Phys. Chem. 63, 401 (2012).

${ }^{11}$ S. Enami, H. Mishra, M. R. Hoffmann, and A. J. Colussi, J. Chem. Phys. 136, 154707 (2012).

${ }^{12}$ D. E. Otten, P. R. Shaffer, P. L. Geissler, and R. J. Saykally, Proc. Natl. Acad. Sci. U.S.A. 109, 701 (2012).

${ }^{13}$ J. Noah-Vanhoucke and P. L. Geissler, Proc. Natl. Acad. Sci. U.S.A. 106, 15125 (2009).

${ }^{14}$ D. Aarts, M. Schmidt, and H. N. W. Lekkerkerker, Science 304, 847 (2004).

${ }^{15}$ A. J. Patel, P. Varilly, S. N. Jamadagni, H. Acharya, S. Garde, and D. Chandler, Proc. Natl. Acad. Sci. U.S.A. 108, 17678 (2011).

${ }^{16}$ P. B. Petersen and R. J. Saykally, Annu. Rev. Phys. Chem. 57, 333 (2006).

${ }^{17}$ P. Jungwirth, Faraday Discuss. 141, 9 (2009).

${ }^{18}$ J. S. Rowlinson and B. Widom, Molecular Theory of Capillarity (Oxford University Press, New York, 1989).

${ }^{19}$ F. Bresme, H. Lehle, and M. Oettel, J. Chem. Phys. 130, 214711 (2009).

${ }^{20}$ H. Mishra, S. Enami, R. J. Nielsen, M. R. Hoffmann, W. A. Goddard, and A. J. Colussi, Proc. Natl. Acad. Sci. U.S.A. 109, 10228 (2012).

${ }^{21}$ H. Mishra, S. Enami, R. J. Nielsen, L. A. Stewart, M. R. Hoffmann, W. A. Goddard, and A. J. Colussi, Proc. Natl. Acad. Sci. U.S.A. 109, 18679 (2012)

${ }^{22}$ S. Enami, M. R. Hoffmann, and A. J. Colussi, J. Phys. Chem. Lett. 1, 1599 (2010).

${ }^{23}$ P. H. Marmottant and E. Villermaux, J. Fluid Mech. 498, 73 (2004).

${ }^{24}$ T. G. Theofanous, V. V. Mitkin, C. L. Ng, C. H. Chang, X. Deng, and S. Sushchikh, Phys. Fluids 24, 022104 (2012).

${ }^{25}$ S. A. Krzeczkowski, Int. J. Multiphase Flow 6, 227 (1980).

${ }^{26}$ D. R. Guildenbecher, C. Lopez-Rivera, and P. E. Sojka, Exp. Fluids 46, 371 (2009).

${ }^{27}$ R. Wang, P. Allmendinger, L. Zhu, A. J. Grohn, K. Wegner, V. Frankevich, and R. Zenobi, J. Am. Soc. Mass Spectrom. 22, 1234 (2011). 
${ }^{28}$ N. Rimbert and G. Castanet, Phys. Rev. E 84, 016318 (2011).

${ }^{29} \mathrm{H}$. Lamb, Hydrodynamics, 6th ed. (Cambridge University Press, 1932).

${ }^{30}$ M. Pilch and C. A. Erdman, Int. J. Multiphase Flow 13, 741 (1987).

${ }^{31}$ L. W. Zilch, J. T. Maze, J. W. Smith, G. E. Ewing, and M. F. Jarrold, J. Phys. Chem. A 112, 13352 (2008).

${ }^{32}$ I. Bhattacharyya, J. T. Maze, G. E. Ewing, and M. F. Jarrold, J. Phys. Chem. A 115, 5723 (2011).

${ }^{33}$ S. Enami, M. R. Hoffmann, and A. J. Colussi, J. Phys. Chem. A 114, 5817 (2010).

${ }^{34}$ J. V. Iribarne and B. A. Thomson, J. Chem. Phys. 64, 2287 (1976).

${ }^{35}$ S. Nguyen and J. B. Fenn, Proc. Natl. Acad. Sci. U.S.A. 104, 1111 (2007).

${ }^{36}$ C. S. Tian, S. J. Byrnes, H. L. Han, and Y. R. Shen, J. Phys. Chem. Lett. 2, 1946 (2011).

${ }^{37}$ P. B. Petersen and R. J. Saykally, J. Am. Chem. Soc. 127, 15446 (2005).

${ }^{38}$ A. C. Stern, M. D. Baer, C. J. Mundy, and D. J. Tobias, J. Chem. Phys. 138, 114709 (2013).

${ }^{39}$ J. Cheng, M. R. Hoffmann, and A. J. Colussi, J. Phys. Chem. B 112, 7157 (2008).

${ }^{40}$ J. Cheng, C. Vecitis, M. R. Hoffmann, and A. J. Colussi, J. Phys. Chem. B 110, 25598 (2006)

${ }^{41}$ R. C. Remsing, J. M. Rodgers, and J. D. Weeks, J. Stat. Phys. 145, 313 (2011).

${ }^{42}$ P. Jungwirth and D. J. Tobias, Chem. Rev. 106, 1259 (2006).

${ }^{43}$ C. Caleman, J. S. Hub, P. J. van Maaren, and D. van der Spoel, Proc. Natl. Acad. Sci. U.S.A. 108, 6838 (2011).

${ }^{44}$ A. P. dos Santos, A. Diehl, and Y. Levin, Langmuir 26, 10778 (2010).

${ }^{45} \mathrm{~J}$. Israelachvilii, Intermolecular and Surface Forces, 3rd ed. (Academic Press, London, 2011)

${ }^{46}$ Y. Marcus, Ion Properties (Marcel Dekker, New York, 1997).

${ }^{47}$ D. A. Walker, B. Kowalczyk, M. O. de la Cruz, and B. A. Grzybowski, Nanoscale 3, 1316 (2011).
${ }^{48}$ F. Behroozi, J. Smith, and W. Even, Am. J. Phys. 78, 1165 (2010).

${ }^{49}$ I. Bako, T. Megyes, S. Balint, T. Grosz, and V. Chihaia, Phys. Chem. Chem. Phys. 10, 5004 (2008).

${ }^{50}$ R. Albert and A. L. Barabasi, Rev. Mod. Phys. 74, 47 (2002).

${ }^{51}$ L. Dougan, S. P. Bates, R. Hargreaves, J. P. Fox, J. Crain, J. L. Finney, V. Reat, and A. K. Soper, J. Chem. Phys. 121, 6456 (2004).

${ }^{52}$ J. H. Guo, Y. Luo, A. Augustsson, S. Kashtanov, J. E. Rubensson, D. K. Shuh, H. Agren, and J. Nordgren, Phys. Rev. Lett. 91, 157401 (2003).

${ }^{53}$ S. Dixit, J. Crain, W. C. K. Poon, J. L. Finney, and A. K. Soper, Nature (London) 416, 829 (2002).

${ }^{54}$ J. A. Morrone and M. E. Tuckerman, J. Chem. Phys. 117, 4403 (2002).

${ }^{55}$ J. A. B. da Silva, F. G. B. Moreira, V. M. L. dos Santos, and R. L. Longo, Phys. Chem. Chem. Phys. 13, 6452 (2011).

${ }^{56}$ A. Fujii, S. Enomoto, M. Miyazaki, and N. Mikami, J. Phys. Chem. A 109, 138 (2005).

${ }^{57}$ A. A. Vartia, K. R. Mitchell-Koch, G. Stirnemann, D. Laage, and W. H. Thompson, J. Phys. Chem. B 115, 12173 (2011).

${ }^{58}$ D. Laage and J. T. Hynes, Science 311, 832 (2006).

${ }^{59}$ M. Pagliai, G. Cardini, R. Righini, and V. Schettino, J. Chem. Phys. 119, 6655 (2003).

${ }^{60}$ J. D. Smith, R. J. Saykally, and P. L. Geissler, J. Am. Chem. Soc. 129, 13847 (2007).

${ }^{61}$ S. J. Irudayam and R. H. Henchman, J. Chem. Phys. 137, 034508 (2012).

${ }^{62}$ R. R. Netz, Eur. Phys. J. E 5, 189 (2001).

${ }^{63}$ F. Bresme, E. Chacon, P. Tarazona, and A. Wynveen, J. Chem. Phys. 137, 114706 (2012)

${ }^{64}$ J. Rottler and A. C. Maggs, Soft Matter 7, 3260 (2011).

${ }^{65}$ F. Despa and R. S. Berry, Biophys. J. 92, 373 (2007).

${ }^{66}$ M. Sharma, R. Resta, and R. Car, Phys. Rev. Lett. 100, 019901(E) (2008).

${ }^{67}$ See supplementary material at http://dx.doi.org/10.1063/1.4803652 for Figures S1 and S3 and Appendixes S1 and S2. 